\title{
Understanding the Chicago Classification: From Tracings to Patients
}

\author{
Francisco Schlottmann, ${ }^{1 *}$ Fernando A Herbella, ${ }^{2}$ and Marco G Patti ${ }^{1}$ \\ ${ }^{1}$ Department of Surgery and Center for Esophageal Diseases, University of North Carolina, Chapel Hill, NC, USA; and ${ }^{2}$ Department of Surgery, \\ Escola Paulista de Medicina, Federal University of Sao Paulo, Sao Paulo, Brazil
}

Current parameters of the Chicago classification include assessment of the esophageal body (contraction vigour and peristalsis), lower esophageal sphincter relaxation pressure, and intra-bolus pressure pattern. Esophageal disorders include achalasia, esophagogastric junction outflow obstruction, major disorders of peristalsis, and minor disorders of peristalsis. Sub-classification of achalasia in types I, II, and III seems to be useful to predict outcomes and choose the optimal treatment approach. The real clinical significance of other new parameters and disorders is still under investigation. (J Neurogastroenterol Motil 2017;23:487-494)

\section{Key Words}

Chicago classification; Esophageal achalasia; Esophageal motility disorders; High-resolution manometry

\section{Introduction}

High-resolution manometry (HRM) provides an intuitive and panoramic view of the proximal digestive physiology from the pharynx to the stomach (Fig. 1). As compared to conventional manometry, HRM determines more comfort and speediness to the test, reduces inter-observer variability, and compensates movements' artefacts. These improvements allow a better evaluation of sphincters relaxation, and the identification of segmental defects of peristalsis not covered by the spacing of sensors in conventional systems. ${ }^{1,2}$

The more comprehensive and more appealing to the eyes HRM plots provoked the imagination of esophageal physiologists to create new investigative parameters and reclassify esophageal motility disorders. This led to the development of an algorithmic scheme for the diagnosis of esophageal motility disorders in esophageal pressure topography plots, under the name of the Chicago classification. ${ }^{3}$ This allowed for improved recognition of motility disorders, and easier interpretation than conventional manometry line tracings.

The Chicago classification was recently revised (version 3.0) to exclude some previous parameters without clear clinical application, define parameters to be used, and classify esophageal motility disorders. $^{4}$

The aim of this study was to review the Chicago classification version 3.0, and assess the clinical implications of the parameters and disorders defined by this classification.

Received: February 22, 2017 Revised: April 26, 2017 Accepted: June 9, 2017

() This is an Open Access article distributed under the terms of the Creative Commons Attribution Non-Commercial License (http://creativecommons. org/licenses/by-nc/4.0) which permits unrestricted non-commercial use, distribution, and reproduction in any medium, provided the original work is properly cited.

${ }^{*}$ Correspondence: Francisco Schlottmann, MD University of North Carolina at Chapel Hill, 4030 Burnett Womack Building, 101 Manning Drive, CB 7081, Chapel Hill, NC 275997081, USA Tel: +1-919-966-8436, Fax: +1-919-966-8440, E-mail: fschlottmann@hotmail.com 

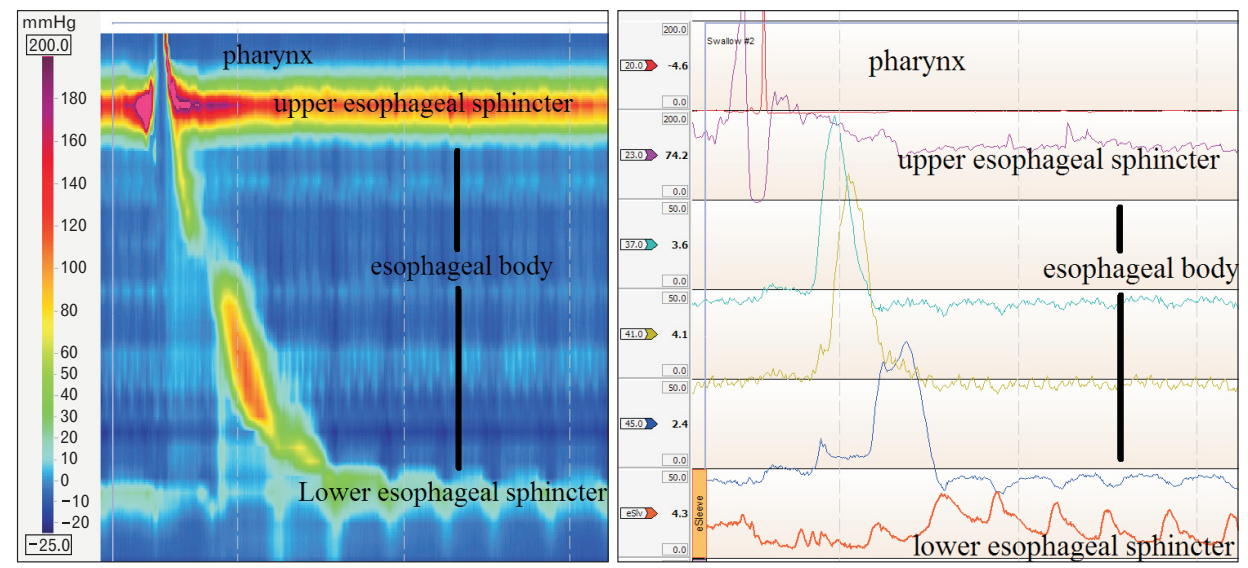

Figure 1. Normal high-resolution manometry plot (left) compared to the same swallow at the conventional manometry (right).

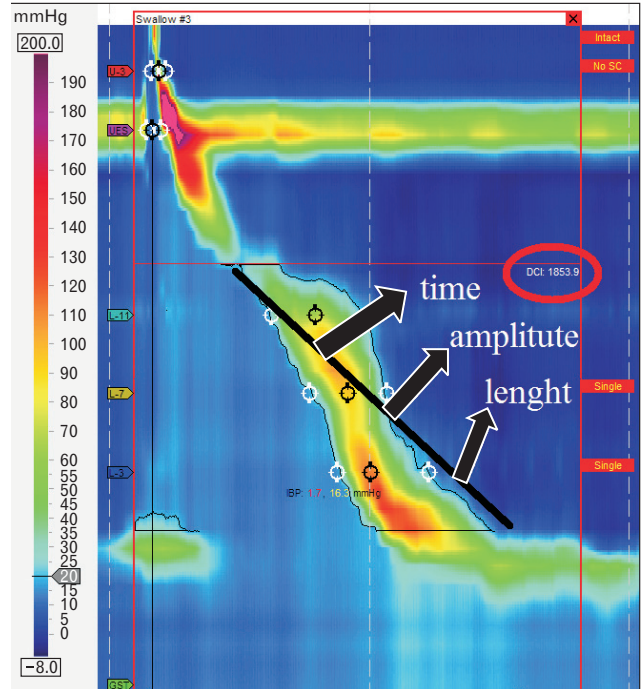

Figure 2. Distal contractile integral (DCI). DCI value is calculated as the product of the mean amplitude of contraction in the distal esophagus $(\mathrm{mmHg})$ times the duration of contraction (seconds) times the length of the distal oesophageal segment $(\mathrm{cm})$ exceeding $20 \mathrm{mmHg}$ for the region spanning from the transition zone to the proximal aspect of the lower esophageal sphincter.

\section{Parameters Evaluated by High-resolution Manometry}

\section{Esophageal Body}

\section{Contraction vigour}

HRM allows the evaluation of contractility not only by amplitude measurement at fixed points, but through a combination of amplitude, time and length of the whole peristaltic wave. This

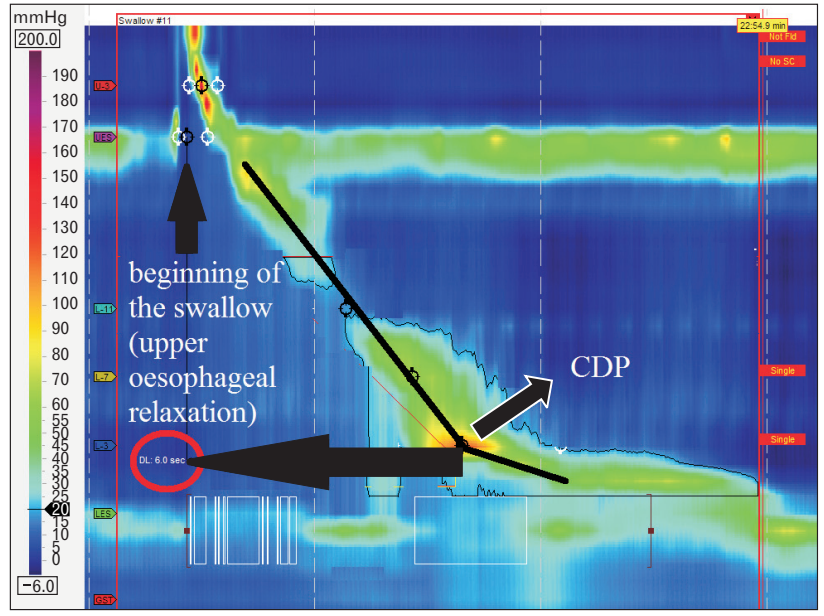

Figure 3. Distal latency (DL) measures objectively the time frame of the wave from the beginning of the swallow (upper esophageal relaxation) to the contractile deceleration point (CDP).

parameter is the distal contractile integral (DCI). DCI value is calculated as the product of the mean amplitude of contraction in the distal esophagus $(\mathrm{mmHg})$ times the duration of contraction (seconds), times the length of the distal esophageal segment (cm) exceeding $20 \mathrm{mmHg}$ for the region spanning from the transition zone to the proximal aspect of the lower esophageal sphincter (LES) (Fig. 2). DCI classifies waves as failed (DCI $<100 \mathrm{mmHg} \cdot \mathrm{sec} \cdot \mathrm{cm}$ ), weak (DCI 100-450 $\mathrm{mmHg} \cdot \mathrm{sec} \cdot \mathrm{cm}$ ), ineffective (failed or weak), normal (DCI 450-8000 $\mathrm{mmHg} \cdot \mathrm{sec} \cdot \mathrm{cm}$ ), or hypercontractile (DCI $>8000 \mathrm{mmHg} \cdot \mathrm{sec} \cdot \mathrm{cm})^{5}$

\section{Peristalsis}

HRM evaluates peristalsis by the distal latency (DL) which measures objectively the timeframe of the wave from the beginning of the swallow (upper esophageal sphincter relaxation) to an inflection 
of the peristaltic axis known as the contractile deceleration point (Fig. 3). Premature contractions are defined with a DL $<4.5$ seconds.

Fragmented contractions are considered segmental defects (break in the $20 \mathrm{mmHg}$ isobaric contour $>5 \mathrm{~cm}$ ) with normal contraction vigour.

Table summarizes esophageal body parameters evaluated with HRM.

\section{Lower Esophageal Sphincter}

\section{Lower esophageal sphincter pressure}

The Chicago classification did not define parameters for LES

Table. Characterization of Esophageal Contractility

\begin{tabular}{ll}
\hline & Contraction vigour \\
\hline Failed & DCI $<100 \mathrm{mmHg} \cdot \mathrm{sec} \cdot \mathrm{cm}$ \\
Weak & DCI $100-450 \mathrm{mmHg} \cdot \mathrm{sec} \cdot \mathrm{cm}$ \\
Ineffective & Failed or weak \\
Normal & DCI $450-8000 \mathrm{mmHg} \cdot \mathrm{sec} \cdot \mathrm{cm}$ \\
Hypercontractile & DCI $>8000 \mathrm{mmHg} \cdot \mathrm{sec} \cdot \mathrm{cm}$ \\
\hline & Contraction pattern \\
\hline Premature & DL $<4.5 \mathrm{sec}$ \\
Fragmented & Break $>5 \mathrm{~cm}$ in the $20 \mathrm{mmHg}$ isobaric \\
& contour with normal DCI \\
Intact & Not achieving the above criteria \\
\hline
\end{tabular}

DCI, distal contractile integral; DL, distal latency. length or basal pressure, but simply recommended assessment of pressure as an average of inspiratory and expiratory values for 3 normal respiratory cycles. Relaxation, however, is measured not by the nadir pressure as previously done with conventional manometry, but with the integrated relaxation pressure (IRP) that corresponds to the mean pressure of 4 seconds of greatest post deglutitive relax-

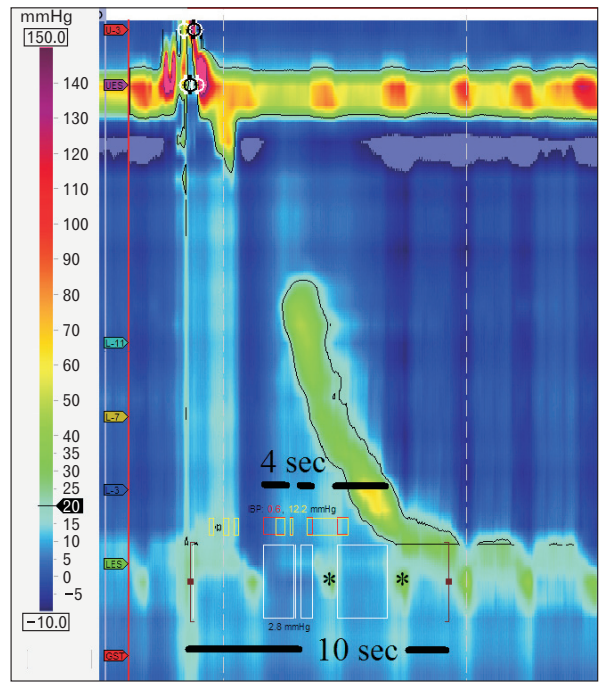

Figure 4. Integrated relaxation pressure (IRP) corresponds to the mean pressure of 4 seconds of greatest post deglutitive relaxation in a 10 seconds gap, triggered at the beginning of a swallow. Note diaphragmatic contraction pressure $(*)$ during relaxation excluded from analysis.

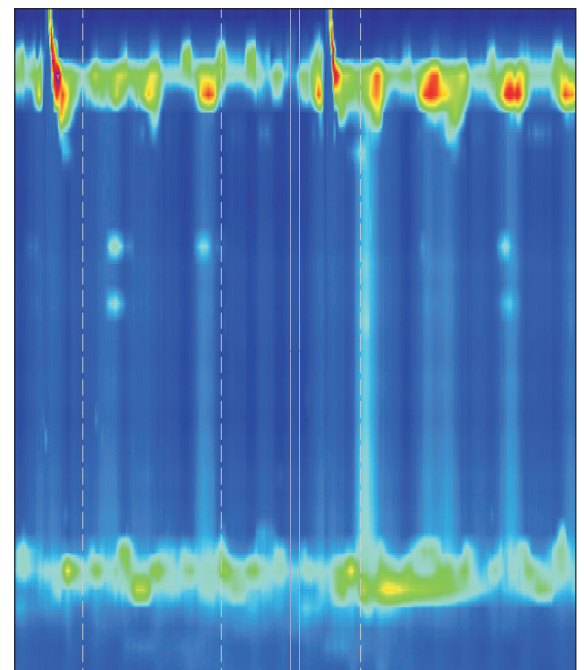

Type I

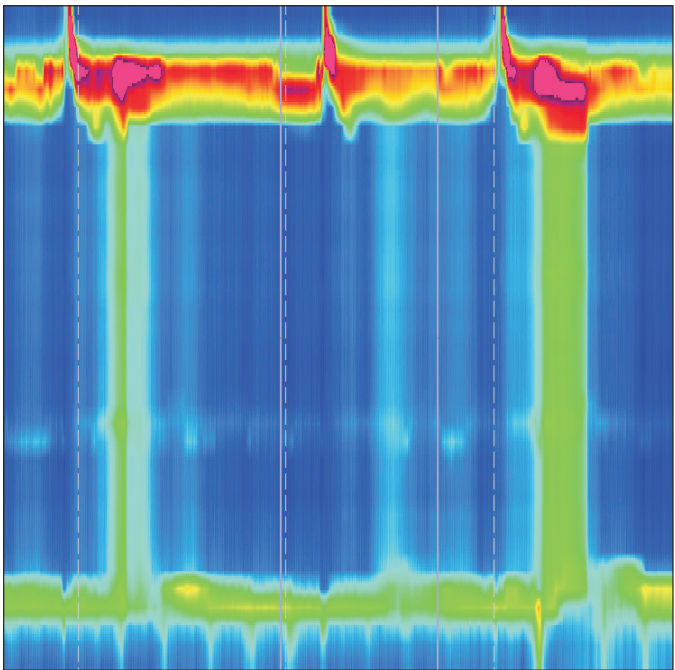

Type II

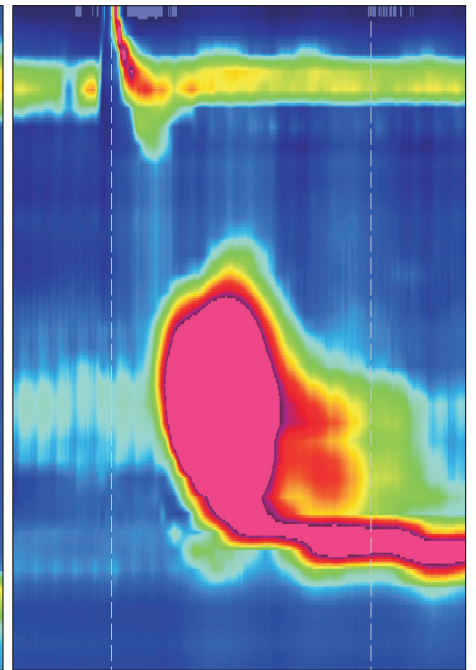

Type III

Figure 5. Achalasia subtypes. Type I: absence of esophageal pressurization; Type II: panesophageal pressurization; Type III: premature contractions (distal latency $<4.5$ seconds). 
ation in a 10 seconds gap, triggered at the beginning of a swallow (Fig. 4). This metric compensates for diaphragmatic contraction during LES relaxation, and eliminates pseudo-relaxation due to movement artefacts.

\section{Intrabolus Pressure Pattern}

Abnormal intrabolus pressure corresponds to regions of esophageal pressurization $>30 \mathrm{mmHg}$. It may be panesophageal (whole esophageal body), compartmentalized (from the contractile deceleration point to the esophagogastric junction [EGJ]) or EGJ pressurization (between the LES and the diaphragm).

\section{Esophageal Motility Disorders}

\section{Achalasia}

Achalasia is defined by aperistalsis and abnormal LES relax-

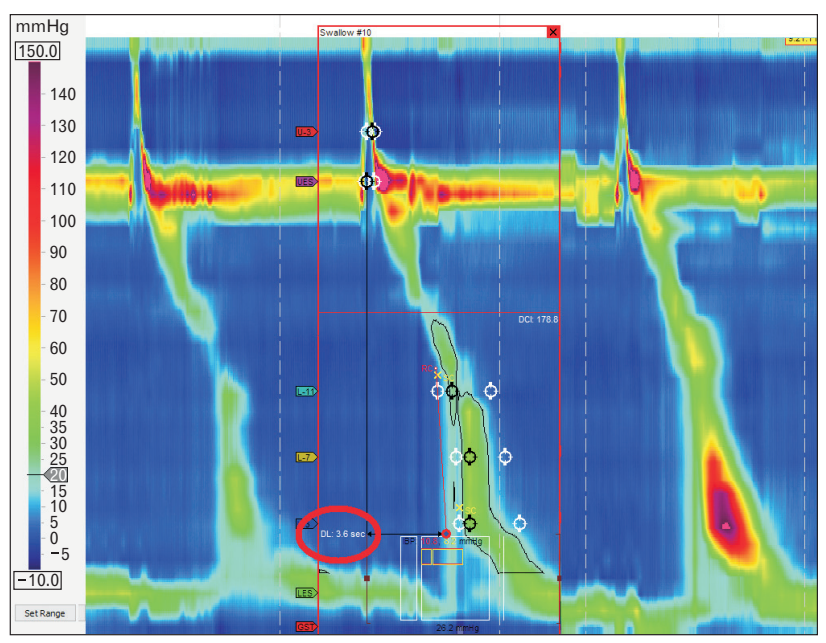

Figure 6. Distal esophageal spasm. Premature contractions (distal latency $[\mathrm{DL}]<4.5$ seconds) in at least $20 \%$ of swallows.
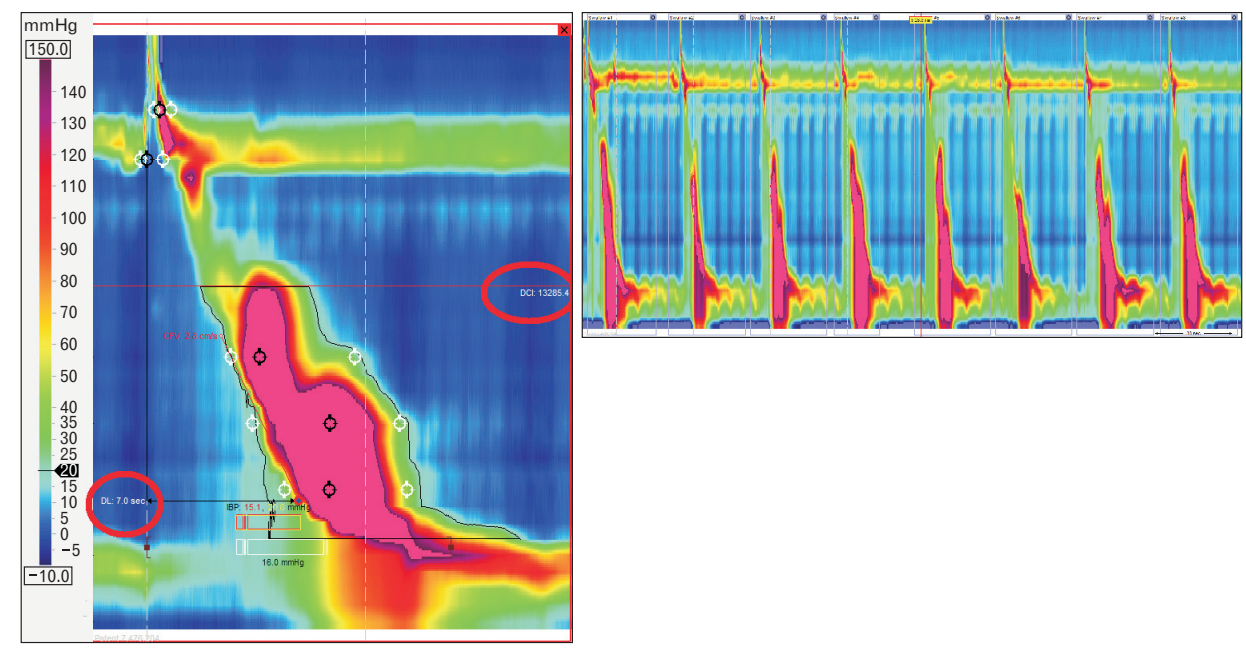

Figure 7. Hypercontractile esophagus (jackhammer esophagus). Distal contractile integral $(\mathrm{DCI})>8000$ $\mathrm{mmHg} \cdot \mathrm{sec} \cdot \mathrm{cm}$ in at least $20 \%$ of swallows and normal distal latency (DL).

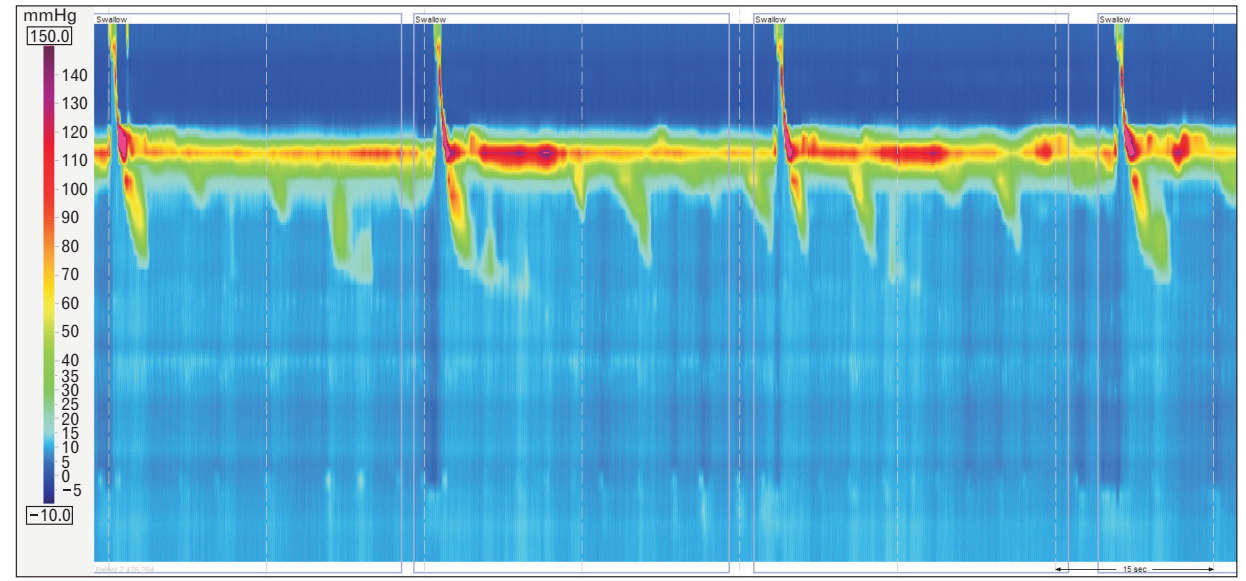

Figure 8. Absent contractility. Aperistalsis in the setting of normal lower esophageal sphincter relaxation (integrated relaxation pressure $<10 \mathrm{mmHg}$ ). 


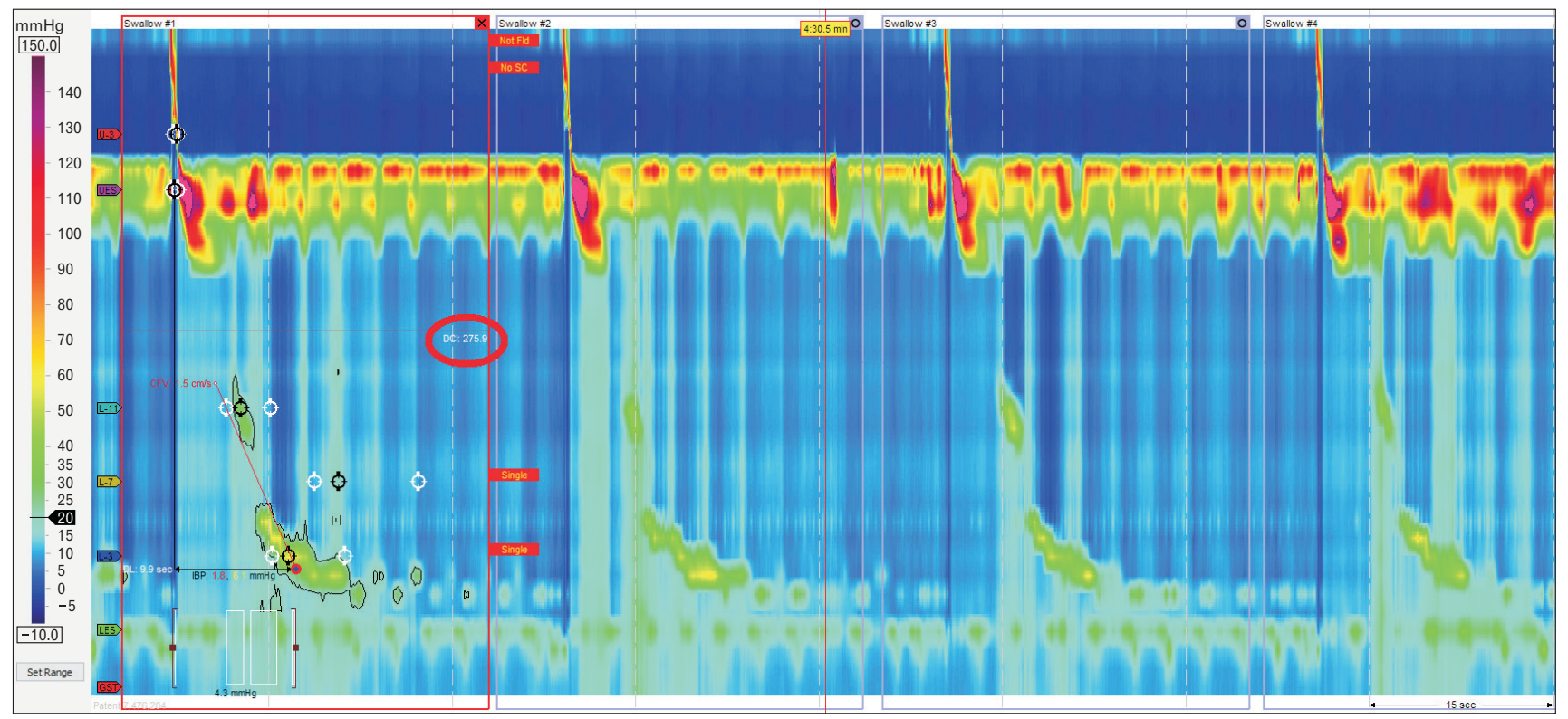

Figure 9. Ineffective esophageal motility. Failed or weak peristalsis in at least $\geq 50 \%$ of swallows. DCI, distal contractile integral.

ation (IRP $>15 \mathrm{mmHg}$ ). The disease is further classified into 3 subtypes (Fig. 5).

Type I: incomplete LES relaxation, aperistalsis and absence of esophageal pressurization.

Type II: incomplete LES relaxation, aperistalsis and panesophageal pressurization in at least $20 \%$ of swallows.

Type III: incomplete LES relaxation and premature contractions (DL $<4.5$ seconds) in at least $20 \%$ of swallows.

\section{Esophagogastric Junction Outflow Obstruction}

EGJ obstruction is characterized by an impaired LES relaxation (IRP $>15 \mathrm{mmHg}$ ) with normal or weak peristalsis.

\section{Major Disorders of Peristalsis}

\section{Distal esophageal spasm}

Distal esophageal spasm (DES) is defined by premature contractions (DL $<4.5$ seconds) in at least $20 \%$ of swallows with a normal IRP (Fig. 6).

\section{Hypercontractile esophagus}

Hypercontractile esophagus (jackhammer esophagus) is characterized by DCI $>8000 \mathrm{mmHg} \cdot \mathrm{sec} \cdot \mathrm{cm}$ in at least $20 \%$ of swallows and normal DL (Fig. 7).

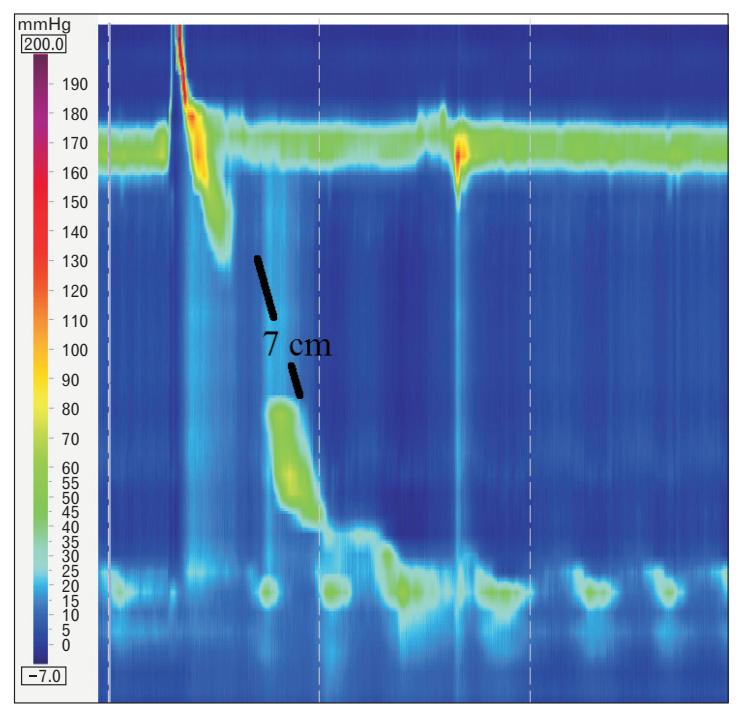

Figure 10. Fragmented peristalsis. $\geq 50 \%$ fragmented contractions with distal contractile integral $(\mathrm{DCI})>450 \mathrm{mmHg} \cdot \mathrm{sec} \cdot \mathrm{cm}$.

\section{Absent contractility}

Absent contractility is characterized by aperistalsis in the setting of normal LES relaxation (IRP $<10 \mathrm{mmHg}$ ) (Fig. 8).

\section{Minor Disorders of Peristalsis}

\section{Ineffective esophageal motility}

Ineffective esophageal motility is defined by $\geq 50 \%$ ineffective 
swallows (failed or weak_DCI $<450 \mathrm{mmHg} \cdot \mathrm{sec} \cdot \mathrm{cm}$ ) (Fig. 9).

\section{Fragmented peristalsis}

Fragmented peristalsis is defined by $\geq 50 \%$ fragmented contractions with normal contraction vigour (Fig. 10).

\section{Impact of High-resolution Manometry on the Management of Esophageal Motility Disorders}

The Chicago classification reclassified motility disorders previously defined by conventional manometry. ${ }^{6}$ The clinical value of this new classification is under scrutiny. A recent publication claims that the Chicago classification has a higher threshold for abnormality, resulting in fewer patients classified as abnormal motility. ${ }^{7}$ On the other hand, a recent study that randomized patients with dysphagia to undergo either HRM or conventional manometry, found a higher proportion of manometric diagnosis in the HRM arm. ${ }^{8}$

\section{Achalasia}

The current main therapeutic options for achalasia include pneumatic dilatation (PD), peroral endoscopic myotomy (POEM), and laparoscopic Heller myotomy (LHM).

The Chicago classification may help to predict the result of treatment. Pandolfino and colleagues ${ }^{10}$ reported that type II achalasia patients were significantly more likely to respond to PD (91\%) or LHM (100\%), as compared to type I (56\% overall) and type III (29\% overall). Concordantly, Salvador et al $^{11}$ evaluated 246 consecutive patients who underwent LHM and found that treatment failure rates were significantly different among the subtypes of achalasia: type I (14.6\%), type II (4.7\%), and type III (30.4\%) (P= $0.0007)$. A recent meta-analysis encompassing 9 studies and 727 patients also showed that type II achalasia was associated with the best prognosis after PD and LHM, while type III achalasia had the worst prognosis. ${ }^{12}$

The Chicago classification may also help selecting the best initial approach for patients with achalasia. Kumbhari and colleagues ${ }^{13}$ reported that in patients with type III achalasia, clinical response was achieved more frequently after POEM (98.0\%), as compared to LHM $(80.8 \%)(P=0.01)$. Recently, Khashab et al ${ }^{14}$ reported their experience with POEM for the treatment of 54 patients with type III achalasia refractory to medical therapy, and showed a 96.3\% clinical success rate. Hence, while in type I and II achalasia both PD and LHM remain as good treatment alternatives, type III achalasia seems to be better managed with POEM, probably due to the ability to a longer myotomy of the thoracic esophagus.

Overall, sub-classification of achalasia in types I, II, and III with the Chicago classification seems to be useful to predict outcomes and choose the optimal treatment approach for this motility disorder.

\section{Esophagogastric Junction Outflow Obstruction}

The definition of EGJ outflow obstruction based solely on the IRP with the exclusion of achalasia allows this diagnosis to be superimposed to other diagnoses dependent of the esophageal body motility. It may be caused by an anatomical abnormality at the cardia (hiatal hernia, diseases of the esophageal wall, etc) or be idiopathic with normal anatomy.

Similar to achalasia, treatment is directed towards relief of the obstruction and can be accomplished by botulinum toxin injection, PD, LHM, or POEM. Both botulinum injection and PD showed good relief of dysphagia but with ephemeral duration. ${ }^{15}$ Scherer and colleagues, ${ }^{16}$ among 1000 HRM diagnosed 16 patients (1.6\%) with EGJ outflow obstruction and treated them with botulinum toxin injection, PD or LHM. Only the 3 patients treated with LHM responded well. ${ }^{16}$ Interestingly, Pérez-Fernández et $\mathrm{al}^{17}$ reported that over one-third of the patients with EGJ outflow obstruction presented a spontaneous resolution of the symptoms, concluding that surgical treatment should be considered with special caution in these patients. In the setting of an anatomic abnormality such as a hiatal hernia, surgical correction is associated with long-lasting and excellent results. ${ }^{18}$

EGJ outflow obstruction is now recognized as a distinct entity in the Chicago classification. However, the real clinical significance of this diagnosis is still uncertain. In fact, it could be an early or incomplete expression of a variant of achalasia. Thus, the exact significance and clinical management of these patients remains unclear.

\section{Major Disorders of Peristalsis}

As the symptoms and the manometric picture of esophageal motility disorders can be due to gastroesophageal reflux disease (GERD), it is of paramount importance to rule out abnormal reflux by $\mathrm{pH}$ monitoring. If GERD is present, either medical or surgical treatment should be directed towards the control of the reflux. ${ }^{19}$

The management of DES remains elusive. The Chicago classification defines this disorder with a new parameter: the DL. Previous reports showed good results in patients with "diffuse esophageal spasm" (Richter classification) ${ }^{6}$ who underwent LHM with an extended myotomy. ${ }^{20,21}$ However, scarce data are available after the new classification defined DES. A review of the publications after 
this definition became publicized showed that botulinum toxin injection in the esophageal body was superior to placebo to relieve dysphagia in patients with DES, and that POEM is a promising treatment for these patients. ${ }^{22}$

The definition of hypercontractile esophagus (jackhammer) was updated in the last version of the Chicago classification to include only cases with $\geq 20 \%$ of swallows with a DCI $>8000$ $\mathrm{mmHg} \cdot \mathrm{sec} \cdot \mathrm{cm}$, excluding a single altered swallow from the definition. Pharmacological relaxation of the smooth muscle with phosphodiesterase- 5 inhibitor or anticholinergic agents has shown symptomatic improvement. ${ }^{23}$ Studies focusing on surgical therapy for hypercontractile esophagus based on the new classification are not available. Previous reports not using HRM or the Chicago classification, however, showed acceptable outcomes after surgical myotomy. ${ }^{24,25}$

Absent contractility is mostly diagnosed in patients with connective tissue diseases. There is no specific treatment to restore or improve peristalsis in these patients. Associated GERD is usually the target of therapy. ${ }^{26}$

\section{Minor Disorders of Peristalsis}

Therapeutic options for ineffective esophageal motility are still limited, as no effective treatment is available to restore impaired esophageal smooth muscle contractility. ${ }^{27}$ Treatment directed towards GERD is helpful when dysmotility is secondary to this disease.

The concept of fragmented peristalsis changed radically from previous versions to the version 3.0. Only large breaks $(>5 \mathrm{~cm})$ with normal peristalsis are included. This is more clinically relevant, since incomplete bolus transit is observed in $100 \%$ of the cases of large breaks but only in $16 \%$ of small breaks. ${ }^{28}$ It is unclear how to treat this finding since there are no studies focusing on the treatment for this disease under these criteria. There are no studies evaluating changes in the motility pattern after therapy for GERD as well, since both conditions are frequently associated.

\section{Conclusions}

HRM and the Chicago classification certainly contributed to a better definition of esophageal motility disorders. Particularly for achalasia, sub-classification in types I, II, and III seems to be useful to predict outcomes and choose the optimal treatment approach. The real clinical significance of other new parameters and disorders is still under investigation.

\section{Financial support: None.}

Conflicts of interest: None.

Author contributions: Francisco Schlottmann, Fernando A Herbella, and Marco G Patti planned conception and design, drafted the article, and approved the final article.

\section{References}

1. Herbella FA, Patti MG. Can high resolution manometry parameters for achalasia be obtained by conventional manometry? World J Gastrointest Pathophysiol 2015;15:58-61.

2. Herbella FA, Armijo PR, Patti MG. [A pictorial presentation of 3.0 Chicago classification for esophageal motility disorders.] Einstein (Sao Paulo) 2016;14:439-442. [English, Portuguese]

3. Kahrilas PJ, Ghosh SK, Pandolfino JE. Esophageal motility disorders in terms of pressure topography: the Chicago classification. J Clin Gastroenterol 2008;42:627-635.

4. Kahrilas PJ, Bredenoord AJ, Fox M, et al. The Chicago classification of esophageal motility disorders, v3.0. Neurogastroenterol Motil 2015;27:160-174.

5. Roman S, Pandolfino JE, Chen J, Boris L, Luger D, Kahrilas PJ. Phenotypes and clinical context of hypercontractility in high-resolution esophageal pressure topography (EPT). Am J Gastroenterol 2012;107:37-45.

6. Richter JE. Oesophageal motility disorders. Lancet 2001;358:823-828.

7. Monrroy H, Cisternas D, Bilder C, et al. The Chicago classification 3.0 results in more normal findings and fewer hypotensive findings with no difference in other diagnoses. Am J Gastroenterol 2017;112:606-612.

8. Roman S, Huot L, Zerbib F, et al. High-resolution manometry improves the diagnosis of esophageal motility disorders in patients with dysphagia: a randomized multicenter study. Am J Gastroenterol 2016;111:372-380.

9. Herbella FA, Moura EG, Patti MG. Achalasia 2016: treatment alternatives. J Laparoendosc Adv Surg Tech A 2017;27:6-11.

10. Pandolfino JE, Kwiatek MA, Nealis T, Bulsiewicz W, Post J, Kahrilas PJ. Achalasia: a new clinically relevant classification by high-resolution manometry. Gastroenterology 2008;135:1526-1533.

11. Salvador R, Costantini M, Zaninotto G, et al. The preoperative manometric pattern predicts the outcome of surgical treatment for esophageal achalasia. J Gastrointest Surg 2010;14:1635-1645.

12. Ou YH, Nie XM, Li LF, Wei ZJ, Jiang B. High-resolution manometric subtypes as a predictive factor for the treatment of achalasia: a metaanalysis and systematic review. J Dig Dis 2016;17:222-235.

13. Kumbhari V, Tieu AH, Onimaru M, et al. Peroral endoscopic myotomy (POEM) vs laparoscopic heller myotomy (LHM) for the treatment of type III achalasia in 75 patients: a multicenter comparative study. Endosc Int Open 2015;3:E195-E201.

14. Khashab MA, Messallam AA, Onimaru M, et al. International multicenter experience with peroral endoscopic myotomy for the treatment of spastic esophageal disorders refractory to medical therapy (with video). Gastrointest Endosc 2015;81:1170-1177. 
15. van Hoeij FB, Smout AJ, Bredenoord AJ. Characterization of idiopathic esophagogastric junction outflow obstruction. Neurogastroenterol Motil 2015;27:1310-1316.

16. Scherer JR, Kwiatek MA, Soper NJ, Pandolfino JE, Kahrilas PJ. Functional esophagogastric junction obstruction with intact peristalsis: a heterogeneous syndrome sometimes akin to achalasia. J Gastrointest Surg 2009;13:2219-2225.

17. Pérez-Fernández MT, Santander C, Marinero A, Burgos-Santamaría D, Chavarría-Herbozo C. Characterization and follow-up of esophagogastric junction outflow obstruction detected by high resolution manometry. Neurogastroenterol Motil 2016;28:116-126.

18. DeLay K, Austin GL, Menard-Katcher P. Anatomic abnormalities are common potential explanations of manometric esophagogastric junction outflow obstruction. Neurogastroenterol Motil 2016;28:1166-1171.

19. Herbella FA, Raz DJ, Nipomnick I, Patti MG. Primary versus secondary esophageal motility disorders: diagnosis and implications for treatment. J Laparaoendosc Adv Surg Tech A 2009;19:195-198.

20. Patti MG, Gorodner MV, Galvani C, et al. Spectrum of esophageal motility disorders: implications for diagnosis and treatment. Arch Surg 2005;140:442-448; discussion 448-449.

21. Leconte M, Douard R, Gaudric M, Dumontier I, Chaussade S, Dousset B. Functional results after extended myotomy for diffuse oesophageal spasm. Br J Surg 2007;94:1113-1118.

22. Roman S, Kahrilas PJ. Distal esophageal spasm. Curr Opin Gastroenterol 2015;31:328-333.

23. Hong YS, Min YW, Rhee PL. Two distinct types of hypercontractile esophagus: classic and spastic jackhammer. Gut Liver 2016;10:859-863.

24. Patti MG, Pellegrini CA, Arcerito M, Tong J, Mulvihill SJ, Way LW. Comparison of medical and minimally invasive surgical therapy for primary esophageal motility disorders. Arch Surg 1995;130:609-615; discussion 615-616.

25. Herbella FA, Tineli AC, Wilson JL Jr, Del Grande JC. Surgical treatment of primary esophageal motility disorders. J Gastrointest Surg 2008;12:604-608.

26. Menezes MA, Herbella FA, Patti MG. Laparoscopic antireflux surgery in patients with connective tissue diseases. J Laparoendosc Adv Surg Tech A 2016;26:296-298.

27. Scheerens C, Tack J, Rommel N. Buspirone, a new drug for the management of patients with ineffective esophageal motility? United European Gastroenterol J 2015;3:261-265.

28. Herbella FA, Tedesco P, Nipomnick I, Fisichella PM, Patti MG. Effect of partial and total laparoscopic fundoplication on esophageal body motility. Surg Endosc 2007;21:285-288. 